\title{
POTENCIALIDADES DA POÉTICA TRANSMÍDIA PARA AUXILIAR O PLANEJAMENTO EDUCACIONAL E O DESIGN INSTRUCIONAL
}

\author{
POTENTIALITIES OF TRANSMEDIA POETICS \\ TO AID EDUCATIONAL PLANNING AND INSTRUCTIONAL DESIGN
}

\author{
Lane Primo ${ }^{1}$, M.Sc. \\ Luciane Maria Fadel ${ }^{2}$, D.Sc. \\ Vânia Ulbricht ${ }^{3}$, D.Sc. \\ (1) Universidade Federal de Santa Catarina (UFSC) \\ e-mail: lanepprimo@gmail.com \\ (2) Universidade Federal de Santa Catarina (UFSC) \\ e-mail: liefadel@gmail.com \\ (3) Universidade Federal de Santa Catarina (UFSC) \\ e-mail: vrulbricht@gmail.com
}

Planejamento didático, narrativa, taxonomia de Bloom revisitada.

Este artigo investiga características da poética transmídia no mundo ficcional da novela digital Inanimate Alice, utilizando o método Close Reading. Os resultados podem auxiliar professores no planejamento didático de situações de aprendizagem e também designers instrucionais no desenvolvimento de projetos educacionais, utilizando a transmídia.

Didatic planning, narrative, revisited Bloom's taxonomy.

This paper presents the results of investigation the characteristics of transmedia poetics in the ficcional world of digital novel Inanimate Alice using Close Reading method. The results can aid teachers to plan learning situations also instructional designers and development staff in order to develop transmedia projects.

\section{Introdução}

A apropriação e uso das Tecnologias da Informação e Comunicação (TICs) nas escolas têm crescido a passos lentos no Brasil. A inserção tem ocorrido de forma gradual por meio dos dispositivos que professores e alunos têm levado para as salas de aula, notadamente os celulares. Parte dessa demora deve-se à necessidade de infraestrutura e qualificação técnica dos professores. De um lado, o Marco Civil da Internet, no artigo 26, prevê que a educação pública inclua formação "integrada a outras 


\section{$16^{\circ}$ \\ ERGODESIGN USIHC CINAHPA}

práticas educacionais, para o uso seguro, consciente e responsável da Internet como ferramenta para o exercício da cidadania, a promoção da cultura e o desenvolvimento tecnológico" [BRASIL, 2014]. No entanto, a realidade mostra-se diferente. O relatório da pesquisa TIC Educação 2015 apontou que as TICs foram utilizadas pelos professores em sala de aula para trabalhos específicos (49\%), trabalhos em grupo (54\%) e promoção de debates ou apresentações (43\%). Esses dados mostram um uso passivo e, portanto, há muito o que melhorar para que a formação integrada seja concretizada, visando a promoção da participação ativa dos estudantes [COMITÊ GESTOR DA INTERNET NO BRASIL, 2016].

Por outro lado, a convergência das mídias, tanto no que tange ao conteúdo quanto em tecnologias e serviços, trouxe oportunidades a serem aproveitadas. As agências de publicidade souberam fazer uso do potencial das mídias para fortalecer a relação das marcas com os clientes por meio da transmídia ${ }^{1}$; porém, ela ainda é pouco explorada no contex to educacional brasileiro. Entretanto, no cenário internacional são encontradas experiências de projetos transmídia na Educação nos diversos níveis - do elementar, correspondente ao básico no Brasil, passando por Jovens e Adultos. Tais projetos envolvem artefatos como games, simulações, objetos de aprendizagem, livros digitais, revistas impressas, animações, apresentações, aplicativos e atividades. Esses artefatos são elaborados utilizando as mídias texto, imagens estáticas e imagens em movimento em suas estruturas [PRIMO et al., 2015]. Na composição destes artefatos acredita-se que o mundo ficcional criado no universo transmídia é um dos elementos que mantém o envolvimento do espectador. Desta maneira, ele (o mundo ficcional) pode ser aproveitado para ampliar as oportunidades de aprender se for conhecido e explorado pelos professores. Estes, por sua vez, podem planejar situações de aprendizagem que provoquem uma

\footnotetext{
${ }^{1}$ Transmídia são "histórias que se desenrolam em múltiplas plataformas de mídia, cada uma delas contribuindo de forma distinta para a compreensão do universo" (JENKINS, 2009, p. 384).
}

$16^{\circ}$ Ergodesign - Congresso Internacional de Ergonomia e Usabilidade de Interfaces Humano Tecnológica: Produto, Informações Ambientes Construídos e Transporte

$16^{\circ}$ USIHC - Congresso Internacional de Ergonomia e Usabilidade de Interfaces Humano Computador

CINAHPA | 2017 - Congresso Internacional de Ambientes Hipermídia para Aprendizagem.

participação mais ativa dos estudantes. Nesse estudo, situação de aprendizagem é um conjunto organizado e articulado de ações do estudante para a construção de um determinado conhecimento ou desenvolvimento de uma ou mais competências [KÜLLER; RODRIGO, 2013]. Diante do exposto, este artigo tem como objetivo apresentar os resultados da análise de um artefato transmídia, utilizando o método Close Reading. Espera-se com os achados contribuir para que professores possam planejar situações de aprendizagem, aproveitando as potencialidades da transmídia para a Educação.

\section{Referencial teórico}

Buscou-se elementos da tecnologia educacional e da comunicação que pudessem formar a tessitura do referencial teórico, envolvendo a transmídia e narrativas a fim de criar a lente para a análise.

Na Educação, o conceito de transmídia ainda é recente. A proliferação das mídias digitais e das tecnologias impulsionaram a criação de conteúdos que podem ser acessados, recriados e utilizados por meio de diversos dispositivos. Desta forma, abre-se para a pluralidade de leituras, assim como espaços para múltiplos centros e discursos variados. Assim, uma narrativa pode expandir-se para jogos, vídeos, histórias em quadrinhos, revistas, entre outros. Entretanto, no contexto do desenvolvimento de recursos transmídia, destacam-se as relações lógicas da narrativa que são caracterizadas pela serialidade, participação da audiência, continuidade e multiplicidade. [FILATRO; CAIRO, 2015].

Pence [2012] afirma que a transmídia tem se tornado importante no discurso escolar devido às mudanças nos ambientes das mídias, entre elas as redes sociais, a computação móvel, a realidade aumentada e a própria transmídia. Aponta que diversos jornais estão se transformando para este formato. Segundo ele, um framework transmídia é baseado em um mundo virtual que é desenhado para ser incompleto. A cultura de rede interage socialmente com esse mundo para criar oportunidades de exploração, interpretação e expansão. Cria-se um ecosistema transmídia, pronto para ser definido e expandido pelos
Realização:

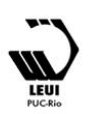




\section{$16^{\circ}$ \\ ERGODESIGN USIHC CINAHPA}

usuários. O uso de framework transmídia para a Educação enfatiza o envolvimento dos estudantes. Segundo ele, para educadores, a transmídia deve enfatizar não o uso da variedade, mas sim a necessidade da audiência (estudantes) de interagir com a narrativa. Acrescenta que transmídia significa mudar com exploração. Compara a um fractal; quanto mais fundo for, mais detalhes são revelados. Isso sugere que o conhecimento é fluido e muda com o tempo.

De acordo com Gosciola [2003], narrativa é uma história contada por alguém, um contar de fatos ou de uma ideia que pode ser a história original ou transportada de uma realidade. No desenvolvimento de uma narrativa há três características fundamentais: $\log o s$ - a estrutura discursiva, a forma; pathos - acontecimentos que levam ao conflito, a profundidade dramática que envolve o espectador; e, ethos - a mensagem ou a manifestação do que está por trás da história. Para Ryan [2006], a definição transmídia da narrativa requer uma conceituação mais ampla, que vai além do verbal. Contudo, essa amplitude deve ser compensada pela redução semântica, caso contrário, todos os textos de todas as mídias serão considerados como narrativas. A autora narratologista propõe a organização das condições da narratividade em quatro dimensões, sendo as três primeiras semânticas e a última pragmática: (1) dimensão espacial: envolve o mundo povoado por existências individualizadas; (2) dimensão temporal: (a) o mundo deve ser situado no tempo sob transformações significativas; (b) as transformações são causadas por eventos físicos não habituais; (3) dimensão mental: (a) um ou mais dos participantes reagem emocionalmente ao estado do mundo; (b) alguns eventos são ações dos agentes para atingir metas e executar planos e, por fim, a (4) dimensão formal e pragmática: (a) a sequência de eventos deve formar uma única corrente causal que caminha para um fim; (b) alguns eventos afirmam os fatos do mundo ficcional e (c) a história comunica algo significativo.

O professor de design de narrativas interativas, James Bizzocchi, propõe um framework para a construção, descrição e análise de narrativas em games que contêm cinco parâmetros: (1) $16^{\circ}$ Ergodesign - Congresso Internacional de Ergonomia e Usabilidade de Interfaces Humano Tecnológica: Produto, Informações Ambientes Construídos e Transporte

$16^{\circ}$ USIHC - Congresso Internacional de Ergonomia e Usabilidade de Interfaces Humano Computador

CINAHPA | 2017 - Congresso Internacional de Ambientes Hipermídia para Aprendizagem. storyworld ou o mundo ficcional - é o ambiente onde o jogo acontece; (2) personagem - são os seres que atuam no mundo; (3) emoção - são tanto as mostradas pelo personagem da história quanto as que são provocadas no interator - ou jogador, no caso dos games; (4) interface narrativa - como a narrativa instancia a aparência e a funcionalidade do design da interface; (5) micronarrativa momentos no fluxo da narrativa que acontecem de forma coerente com o contexto maior do game [BIZZOCCHI, 2007].

Para finalizar, ainda no contexto dos games e histórias, Henry Jenkins, professor de comunicação, jornalismo e arte cinematográfica, defende uma arquitetura narrativa. Pauta-se em documentos os quais mostram historicamente que a construção do espaço para o mundo da história é um dos aspectos de maior interesse e investimento dos designers de game, ultrapassando inclusive a criação da trama ou do personagem. Relata que na transmídia, quando filmes são adaptados para games, o processo envolve traduzir eventos do filme para ambientes dentro do game; de igual maneira, revistas de game quando descrevem a experiência de gameplay precisam de um esforço maior para disponibilizar informação a fim de reproduzir o mapa do mundo do game do que o esforço para recontar a narrativa. Sugere que os designers de games estudem técnicas de ambientação da contação de histórias. Desta forma, abrem-se possibilidades para criar pré-condições de experiências narrativas imersivas por meio da adoção de uma das quatros formas, a saber: (1) criação de espaços evocativos - significa que o espaço da história é capaz de reproduzir na imaginação ou de trazer a lembrança de associações narrativas preexistentes; (2) espaço de representação - em que os interatores possam atuar ou testemunhar os eventos narrativos da história. Por exemplo, os objetivos, os conflitos e os incidentes localizados indicam o mapa do personagem e as ações a serem realizadas ao longo do percurso; (3) incorporação das narrativas estão, no geral, presentes nos formatos de investigação ou histórias de conspiração. As dicas e pistas deixadas no espaço ajudam a reconstruir as narrativas dos eventos passados; e (4) narrativas emergentes - potencialidade para que o interator 


\section{$16^{\circ}$ \\ ERGODESIGN USIHC CINAHPA}

possa construir sua própria história a partir de estados emocionais, relacionamentos dos personagens, entre outros aspectos do mundo ficcional. Vale ressaltar que qualquer seleção sobre o design e a organização do espaço traz consequências para a narrativa, respectivamente, imersão em um mundo ficcional familiar (espaços evocativos), história estruturada ao redor do movimento de um personagem pelo espaço (espaço de representação), espaço com conteúdos que precisam ser decifrados (incorporação das narrativas) e a construção de histórias a partir das atividades dos interatores (narrativas emergentes) [JENKINS, 2004]. Apesar das contribuições dos autores abordarem o contexto dos games, elas foram escolhidas porque podem ser utilizadas em outros tipos de artefatos e situações.

\section{Método}

A investigação enquadra-se como uma pesquisa básica com abordagem qualitativa. Ela é exploratória e prescritiva e envolve o estudo de um artefato, utilizando o método Close Reading e revisão bibliográfica. O Close Reading “[...] transita entre a microestética (o texto propriamente dito e sua exegese - explicação ou interpretação cuidadosa) e a macroestética (a diegese - a realidade criada pelo autor - e o resultado estético desse texto) de uma obra literária, buscando na primeira os arrimos da segunda" [WAKI, 2015, p. 21]. Prose [2013] defende que aprende-se a dar sentido quando em um processo de leitura assimila-se uma palavra depois de outra, uma frase de cada vez, e aí presta-se atenção ao que cada palavra e frase transmitem. Os autores citados tratam do texto literário; porém, para este estudo, considera-se uma visão mais ampla de texto. Entende-se que texto é uma mensagem em qualquer código; sendo assim, pode-se chamar de textos os fenômenos culturais como filmes, danças, pinturas, entre outros [SANTAELLA, 2013]. Desta maneira, para analisar a novela digital que é o objeto deste estudo, ao aplicar o close reading, em vez de palavras e frases, utilizar-se-á cenas, personagens, efeitos e narrativa para buscar como as conexões levam a um sentido. Para este artigo optou-se por estudar o aspecto mundo ficcional feito pela lente da poética da transmídia. Vale $16^{\circ}$ Ergodesign - Congresso Internacional de Ergonomia e Usabilidade de Interfaces Humano Tecnológica: Produto, Informações Ambientes Construídos e Transporte

$16^{\circ}$ USIHC - Congresso Internacional de Ergonomia e Usabilidade de Interfaces Humano Computador

CINAHPA | 2017 - Congresso Internacional de Ambientes Hipermídia para Aprendizagem.

esclarecer que poética é o estudo de um trabalho finalizado como resultado de um processo de elaboração em termos de composição, função, efeitos e usos [BORDWEL, 2008 citado por TANENBAUM, 2015].

Os passos do close reading realizados foram: (1) observação do objeto de estudo, cuja interação foi feita três vezes sem qualquer anotação; (2) nas observações posteriores, procedeu-se à captura de telas para identificação das cenas, assim como informações e detalhes acerca dos personagens, efeitos e narrativas; (3) análise de evidências ou características relacionadas ao mundo ficcional da história sob a lente da poética transmídia de Jenkins [2004]. Para análise, optou-se pela lente da poética transmídia devido à aderência a este tema e ao interesse em aprofundar o assunto. O critério de seleção do objeto de estudo foi o de relevância indicado pelas referências na literatura e adequação às características de transmídia descritas por Filatro e Cairo [2015]. Para a revisão bibliográfica foram pesquisados os autores de referência de acordo com as temáticas encontradas no processo de observação e análise. Na seleção do artefato transmidiático utilizou-se as relações lógicas da narrativa de Filatro e Cairo [2015]. Na análise, as contribuições teóricas de Gosciola [2003], Bizzocchi [2007), Ryan [2006] e Jenkins [2004]. Para sintetizar, a Figura 1 ilustra de forma esquemática o tratamento dos tópicos abordados no referencial.

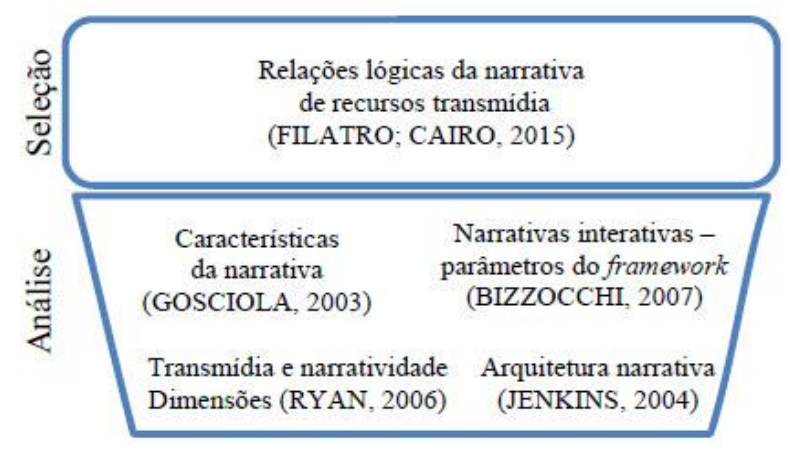

Figura 1- Tratamento do referencial teórico. Fonte: Elaboração das autoras.

\section{Resultados}

Na busca pelo objeto de estudo, encontrou-se Inanimate Alice citado em diversos artigos como
Realização:

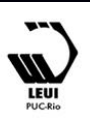




\section{$16^{\circ}$ \\ ERGODESIGN USIHC CINAHPA}

exemplo de projeto transmídia [PENCE, 2012; RODRIGUES; BIDARRA, 2014]. Segundo Rodrigues e Bidarra [2014], é considerado como ferramenta transmídia para a alfabetização midiática de estudantes e professores, sendo utilizada para explorar diferentes áreas e assuntos. De acordo com Pence [2012, p. 135], o projeto Inanimate Alice é um framework transmídia, cuja narrativa é constituída de texto, imagens, música, efeitos sonoros, quebra-cabeças e jogos baseados na interação do usuário. É aberta, o que permite que os usuários, a partir do mundo proposto, criem novas e independentes visões desse mundo.

Inanimate Alice apresenta as seguintes características transmídia [FILATRO; CAIRO, 2015]: é desenvolvida em série, favorecendo o engajamento do público infantojuvenil no acompanhamento do crescimento da protagonista; os desdobramentos permitem a participação do público em redes sociais, blogs ou outro tipo de interatividade e construção coletiva; é passível de continuidade tanto dos episódios da série quanto das atividades a serem desenvolvidas; e, por fim, as produções dos estudantes, fruto dos desdobramentos das situações de aprendizagem que usam o mundo ficcional de Alice, são materializadas em diferentes mídias - texto, imagens estáticas e imagens em movimento.

\subsection{Inanimate Alice}

Inanimate Alice é uma novela digital, criada pela novelista Kate Pullinger e o artista digital Chris Joseph, com a produção de Ian Harper. É utilizada pelos educadores como ferramenta para a introdução da alfabetização midiática na sala de aula. O projeto ganhou o prêmio de melhor website de ensino e aprendizagem, em 2012. A heroína Alice vive com seus pais e, por causa da atividade profissional do pai, precisa morar em locais diferentes. A novela conta os desafios de Alice em diversos países. Atualmente, são seis episódios: (1) China, Alice com 8 anos; (2) Itália, Alice com 10 anos; (3) Rússia, com 13 anos; (4) Inglaterra, com 14 anos; (5) Inglaterra, com 16 anos e (6) A última estação de gasolina, com 19 anos. Para este estudo, optou-se analisar o episódio 1, por ser inicial. $16^{\circ}$ Ergodesign - Congresso Internacional de Ergonomia e Usabilidade de Interfaces Humano Tecnológica: Produto, Informações Ambientes Construídos e Transporte

$16^{\circ}$ USIHC - Congresso Internacional de Ergonomia e Usabilidade de Interfaces Humano Computador

CINAHPA | 2017 - Congresso Internacional de Ambientes Hipermídia para Aprendizagem.

\subsection{Close Reading à luz do referencial teórico}

Inanimate Alice, episódio 1, China é composto de textos, imagens e sons. A tela inicial orienta algumas ações, dentre elas: ligar o som, usar o mouse para avançar quando aparecer o sinal de duas pontas de seta para direita " $>>$ ", aviso informando que em algumas telas será necessário realizar alguma ação para a continuidade da história, usar os ícones que ficarão do lado direito da tela para voltar às seções anteriores e verificar o tempo de duração do episódio. A informação inicial estima cinco minutos para assistir ao episódio; porém, a média foi de oito minutos e meio nas observações realizadas. A tela de orientação desaparece após o avanço para o início da história e não é mais retomada. Essas orientações iniciais fazem parte do design instrucional. De acordo com Filatro e Cairo [2015, p. 75], um dos grandes desafios de produzir conteúdos educacionais é decidir quais linguagens e canais de comunicação utilizar, assim como saber de que maneira combiná-los, seja multi, hiper ou transmídia. O primeiro episódio foi desenvolvido em 2005. Atualmente, os designers criam as telas de apresentação utilizando um mínimo de texto. As orientações têm sido substituídas por efeitos visuais ou sonoros. No caso, o ícone de avançar teria um efeito visual para chamar a atenção do usuário em vez da explicação em texto, levando-o a inferir a ação de toque ou clique.

Nos próximos parágrafos serão relatadas as observações sobre alguns dos elementos que constroem o mundo ficcional da história, incluindo as cenas, personagens, efeitos e a narrativa.

No cinema, teatro, TV e na literatura, cena é cada uma das unidades de ação que constituem um filme, narrativa, peça, novela ou romance [MICHAELIS, 2016]. Na produção de conteúdos educacionais, mais especificamente de vídeos, cena é a combinação de planos de ação relacionados com uma ação principal [FILATRO; CAIRO, 2015]. Para Gosciola [2003, p.132], cena é o que define uma situação espaço-temporal de outra. Ao considerar esta última, em Inanimate Alice, episódio 1, pode-se destacar algumas cenas principais: (1) o desaparecimento do pai, (2) a busca por ele e (3) o encontro. Essas cenas 


\section{$16^{\circ}$ \\ ERGODESIGN USIHC CINAHPA}

caracterizam o pathos [GOSCIOLA, 2003], definem as dimensões temporais [RYAN, 2006] e o pano de fundo do mundo ficcional no qual a história de Alice se desenvolve [BIZZOCCHI, 2007]. Elas foram desdobradas em ações paralelas que Bizzocchi [2007] as chama de micronarrativas. Por exemplo: no desaparecimento do pai, Alice apresenta o local onde vive com seus pais, quem são eles, o que fazem, entre outras informações. Isso ocorre de forma similar nas outras cenas. As micronarrativas criam um desvio, mas retornam para a linha principal, complementando as lacunas e dão margem para novas possibilidades que podem ser criadas pelo interator. Tanto as cenas quanto as micronarrativas deixam sinais que podem ser associados aos conteúdos das disciplinas. Por exemplo, Geografia e História para conhecer os locais citados, saber sobre cultura, economia, relações internacionais, entre outros.

No episódio participam os seguintes personagens: Alice, a heroína; Ming, a mãe, artista e pintora; e John, o pai, trabalha com a exploração de poços de petróleo. Alice apresenta Brad, um amigo imaginário criado por ela no Ba-xi, Figura 2 . Tratase de um dispositivo móvel com o qual ela interage para digitar textos, desenhar, tirar fotos, enviar mensagens, usar aplicativo de mapeamento para geolocalização, entre outras ações comuns a esse tipo de aparelho. O uso do dispositivo abre oportunidades para explorar o desenvolvimento de competências na utilização de mídias.

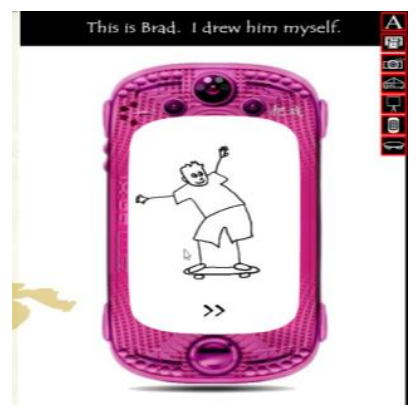

Figura 2 - Brad desenhado por Alice no Ba-xi. Fonte: Inanimate Alice, ep. 1, China [2005].

A dimensão espacial [RYAN, 2006] do universo de Alice mostra sua aventura aos 8 anos, dependente dos pais, vivenciando mudanças de cultura e aparentando sentir falta de vínculos. A mãe, pintora, e o pai, que $16^{\circ}$ Ergodesign - Congresso Internacional de Ergonomia e Usabilidade de Interfaces Humano Tecnológica: Produto, Informações Ambientes Construídos e Transporte

$16^{\circ}$ USIHC - Congresso Internacional de Ergonomia e Usabilidade de Interfaces Humano Computador

CINAHPA | 2017 - Congresso Internacional de Ambientes Hipermídia para Aprendizagem. explora petróleo, atuam nesse mundo [BIZZOCCHI, 2007]. A relação com a mãe é a mais próxima, o que alimenta sua veia artística. A relação com o pai estimula seu lado mais racional e tecnológico. Os nomes dos pais (Ming e John) sugerem a união de duas culturas, o que abre espaço para temas, como: multiculturalidade, globalização, artes, gastronomia, como possibilidades para estudo e pesquisa.

Ryan [2006] e Bizzocchi [2007] tratam as emoções como pertencentes ao mundo ficcional. Para ela, faz parte da dimensão mental e, para ele, é um dos cinco parâmetros do framework de análise já citado anteriormente. No episódio, as emoções vivenciadas pelos personagens são compartilhadas pelos interatores em diversos pontos. Em algum momento da vida real do interator houve uma mudança em que o pertencimento foi questionado, alguém da família pode ter sumido ou deixado de dar notícias, provocando ansiedade. Em algumas passagens, a emoção está implícita, como na criação de um amigo imaginário e o desejo de ter um cachorro. Esses são sinais que podem ser interpretados como momentos de fuga da realidade solitária de Alice, uma forma de expressar seu desejo de ter amigos ou uma outra vida. Tais passagens podem gerar a empatia do interator ou trazer a lembrança de experiência similar, o que Jenkins [2004] atribui como espaço evocativo.

No cinema e na hipermídia, os efeitos visuais são recursos aplicados tanto para criar impacto como também atribuir dramaticidade à informação. Os efeitos de transição são utilizados na passagem de uma ação para outra ou de uma tela para outra. Eles existem no cinema desde seu início, são utilizados para caracterizar passagem de tempo ou marcar a finalização de uma cena. Para ilustrar, é comum observar quando uma cena desaparece gradualmente (fade-out) enquanto outra surge para substituí-la (fade-in), também quando elas se fundem ou se dissolvem [GOSCIOLA, 2003]. De forma similar, os efeitos sonoros causam impacto, chamam a atenção para algum ponto da cena. Na edição de vídeos, a etapa de sonorização divide-se em: (a) díálogos - caracterizados pelas falas dos personagens; (b) trilha sonora - composta pela parte musical e (c) ruídos, que são os efeitos sonoros [FILATRO; CAIRO, 2015]. A combinação de 


\section{$16^{\circ}$ \\ ERGODESIGN USIHC CINAHPA}

efeitos de imagem e som criam sensações diferenciadas. Essas sensações auxiliam na composição da história que envolve o espectador.

Em Inanimate Alice há diversos efeitos visuais e sonoros. Em sua grande maioria, apontam para o clima de suspense. Verifica-se que os movimentos são rápidos e de corte. As telas são escuras e cortam para a próxima, algumas vezes provocando um sobressalto. Ao texto foi aplicado efeito de estremecimento que deixa as letras borradas em um movimento rápido. Na mesma sequência do texto ouve-se um barulho de interferência de sinal elétrico em intervalos regulares, o qual passa a sensação de picos de tensão que refletem no movimento tremido das letras, Figura 2.

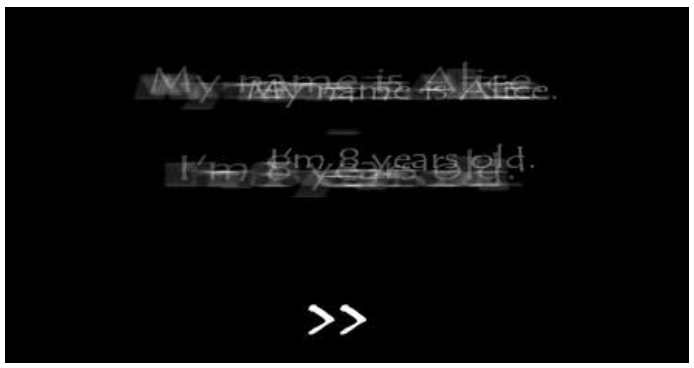

Figura 2- Recorte de captura de tela. Imagem do efeito de tremor aplicado ao texto. Fonte: Inanimate Alice, ep. 1, China [2005].

Nos momentos de tensão, o silêncio e as músicas são sobrepostos e cortados por interferências, barulhos e chiados. Percebe-se a alteração da velocidade tanto nos barulhos quanto na mudança das trilhas musicais.

Ainda considerando os efeitos, destacam-se alguns exemplos de cenas consideradas emblemáticas: o primeiro ocorre na cena (1), quando Alice descreve sua mãe. Especificamente, a microcena na qual a mãe demonstra preocupação com $o$ desaparecimento do pai, o barulho de rotação de motor, a corrente elétrica e os ruídos de interferência são emitidos num tom mais baixo. Ao mesmo tempo, o som de uma música suave em instrumento de cordas (parece ser uma harpa) está em um tom mais alto, indicando primeiro plano.

A tela está dividida em duas e no sentido vertical. Esse recurso é conhecido como Split Screen. Ele é utilizado para indicar acontecimentos que ocorrem $16^{\circ}$ Ergodesign - Congresso Internacional de Ergonomia e Usabilidade de Interfaces Humano Tecnológica: Produto, Informações Ambientes Construídos e Transporte

$16^{\circ}$ USIHC - Congresso Internacional de Ergonomia e Usabilidade de Interfaces Humano Computador

CINAHPA | 2017 - Congresso Internacional de Ambientes Hipermídia para Aprendizagem. de forma simultânea, porém, separados de alguma maneira - pela distância ou pelo tempo [FILATRO; CAIRO, 2015]. À esquerda, pinceladas em tons róseos e beges preenchem o espaço do fundo branco. As pinceladas são transparentes e acumulam pontos mais opacos à medida que se sobrepõem; porém, mantêm a leveza. Â direita, no fundo preto, o texto informa que a mãe chama-se Ming e que ela pinta enquanto Alice desenha, Figura 3. Vale notar que, ao mesmo tempo em que os ruídos soam, as letras do texto estremecem indicando a interferência. A divisão das telas sugere a ideia de contraste entre calmaria e tensão, tanto nas imagens quanto nos sons. $\mathrm{Na}$ mesma Figura 3, do lado direito estão os ícones das seções percorridas pelo espectador. Nesta específica, o ícone representa uma tela de pintura. Os ícones anteriores representam o A de Alice, o calendário - tempo, fotos - do local do trabalho do pai, a casa - o acampamento em que vive - e a tela, apresentação da mãe.

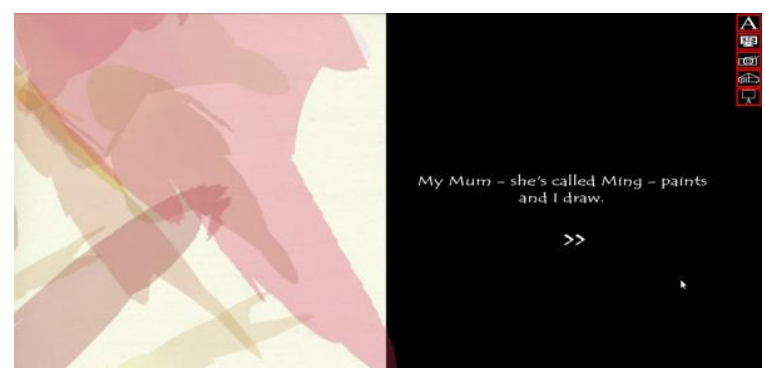

Figura 3 - Tela em que Alice descreve a mãe. Fonte: Inanimate Alice, ep.1, China [2005].

O segundo exemplo é a representação da cena 2 - a busca pelo pai - a qual envolveu duas telas e ações do espectador que, neste ponto, passa a ser interator. A divisão horizontal mostra o cenário em paralaxe nas duas partes, Figura 4.

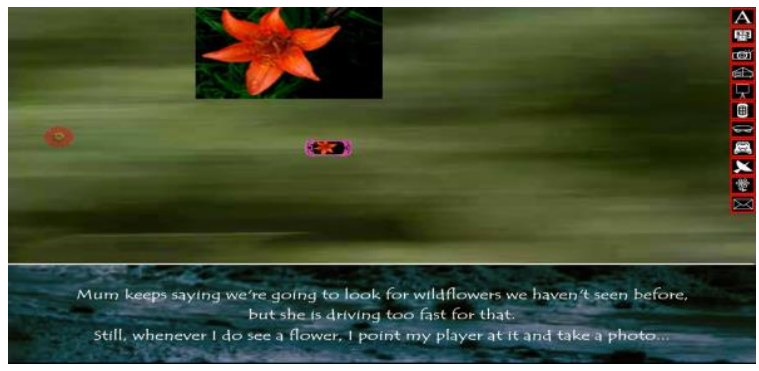

Figura 4 - Tela em que Alice e a mãe procuram o pai. Fonte: Inanimate Alice, ep.1, China [2005].
Realização:
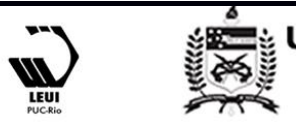


\section{$16^{\circ}$ \\ ERGODESIGN USIHC CINAHPA}

$16^{\circ}$ Ergodesign - Congresso Internacional de Ergonomia e Usabilidade de Interfaces Humano Tecnológica: Produto, Informações Ambientes Construídos e Transporte

$16^{\circ}$ USIHC - Congresso Internacional de Ergonomia e Usabilidade de Interfaces Humano Computador

CINAHPA | 2017 - Congresso Internacional de Ambientes Hipermídia para Aprendizagem.
Na parte maior superior, a visão de movimento do vidro do carro passa muito rápido, não é possível identificar a paisagem. Ela representa a perspectiva de Alice. De forma aleatória, imagens de flores em opacidade reduzida surgem em locais distintos uma por vez. A mãe de Alice dirige muito rápido. Ela pede que Alice fotografe as flores com o Ba-xi. À medida que o interator passa o mouse ou apontador sobre uma flor, o barulho de um disparo de câmera é ouvido, o que significa que Alice capturou uma foto. Esta é posicionada na parte superior da tela. Ela não consegue ver as flores pela janela do carro, mas obedece a mãe e aciona o Ba-xi para pegar alguma coisa. A representação do Ba-xi acompanha o ponteiro do mouse ou apontador do interator. A parte inferior da tela é menor. Nela, a paisagem passa mais lenta. $O$ tom é de cor fria, azulada, insinuando a iluminação de noite de lua cheia. A trilha sonora de instrumentos de cordas começa suave e acelera. Um coral de vozes, aparentemente de crianças, entoa uma espécie de mantra que silencia quando as cordas são tocadas. A trilha sonora continua suave, tanto as vozes do coral quanto o som dos instrumentos, mas aceleram à medida em que uma bateria entra e dá $\mathrm{o}$ ritmo mais rápido. As letras continuam a tremer, porém não é o ruído da interferência que dispara e, sim, outro fenômeno não identificado, marcado pelo ritmo acelerado do coral e dos instrumentos (cordas e bateria). Verifica-se nessa passagem a dimensão mental [RYAN, 2006], as angústias da mãe são sentidas por Alice, mesmo quando ela tenta disfarçar pedindo que a menina tire fotos para desviar o foco tenso da preocupação. No entanto, as pistas deixadas contradizem a linguagem corporal e a fala da mãe.

Para finalizar, observou-se o episódio no aspecto da narrativa. Tomando emprestados os conceitos de narrativa de Gosciola [2003] e Ryan [2004], destacam-se no episódio 1 de Inanimate Alice na China, o tempo da narrativa e a pessoa. Alice narra a maioria dos eventos no tempo presente e refere-se à primeira pessoa do plural porque inclui sua mãe nas ações. Somente quando refere-se a seus desejos e impressões é que ela fala em primeira pessoa do singular. Essas características da personagem Alice de contar a história de uma passagem da sua vida a partir de sua percepção e sem a presença de um narrador é o que Ryan [2006] identifica como modo de narrativa mimético interno. O passado é retratado quando ela fala sobre Brad, que foi desenhado no Ba-xi. Alice o referencia em terceira pessoa quando descreve o veículo da família, o Jeep. O tempo futuro foi adotado nas possibilidades, por exemplo, o registro da localização no dispositivo poderá ajudar a encontrar o pai. Em futuro do pretérito as ações que gostaria de fazer. Mas não pode por obedecer às ordens da mãe de não usar o Ba-xi porque ela estava irritada. Esse tempo também foi utilizado para as ações que ela poderia realizar se morasse na cidade.

O segundo destaque é a perspectiva de Alice com relação aos acontecimentos e demais personagens. Ela percebe a preocupação, a ansiedade e o temor da mãe nas situações vivenciadas. A mãe tentou disfarçar a preocupação ao dizer que o pai sabia o que estava fazendo e logo retornaria. Outra evidência é a passagem em que a mãe lhe diz que estão buscando flores não conhecidas, porém as atitudes demonstraram o oposto. Elas saíram à noite e a mãe dirigia muito rápido, o que não permitia a visualização de qualquer espécie de flor. Alice também percebe o medo da mãe ao dirigir num lugar acidentado e com pouca luz. Ao afirmar que nunca saíram para procurar o pai, ela denota a situação inusitada e preocupante.

O Jeep aparenta ser um escudo protetor, pois as características são descritas como grandes e poderosas. Dá a impressão de ser uma forma de compensar a tensão da situação. O escuro amedronta, mesmo com a proteção de um carro equipado com luzes potentes, mas que parecem não iluminar o suficiente. Poder usar o Ba-xi e ver o Brad seria um alento para Alice. No entanto, sua frustração e insegurança ficaram evidentes na sua fala; porém, sua mãe lhe disse que ela deveria desligá-lo porque, provavelmente, o barulho do teclado a irritava. Sem ter o que ver pela janela do Jeep, a válvula de escape de Alice foi a imaginação. Ela começou a pensar no que poderia fazer se morasse em uma cidade.

A dimensão formal e pragmática de Ryan [2006], é evidenciada, pois a sequência de eventos apresenta uma linha em direção ao objetivo do episódio, que 


\section{$16^{\circ}$ \\ ERGODESIGN USIHC CINAHPA}

é encontrar o pai. Identifica-se também que a interface narrativa (BIZZOCCHI, 2007] é declarativa na primeira tela, que orienta a navegação. Nas demais cenas, a aparência, os efeitos, tempo para aparecimento dos elementos são coordenados pela sequência de fatos e pistas.

Na perspectiva do planejamento didático, conteúdos de Português (tempos verbais e usos, redação e escrita criativa, entre outros), assim como a produção de textos em diferentes mídias, entre elas fotografia, vídeo, animação e arte, propiciam o uso de linguagens e formatos diversificados para o desenvolvimento de novas competências.

Em suma, o Quadro 1 apresenta alguns dos aspectos identificados no mundo ficcional de Inanimate Alice, assim como as possibilidades de exploração.

\begin{tabular}{|c|c|c|}
\hline $\begin{array}{l}\text { Elementos e aspectos } \\
\text { encontrados }\end{array}$ & Evidências & $\begin{array}{l}\text { Conteúdos e } \\
\text { temas a explorar }\end{array}$ \\
\hline $\begin{array}{l}\text { Cenas } \\
\text { - Pathos }{ }^{(1)} \\
\text { - Dimensão temporal }{ }^{(2)} \\
\text { - Micronarrativas }\end{array}$ & $\begin{array}{l}\text { 1. Desaparecimento } \\
\text { do pai; } \\
\text { 2. A busca; } \\
\text { 3. O encontro. }\end{array}$ & $\begin{array}{l}\text { Português; } \\
\text { Inglês; } \\
\text { Geografia; } \\
\text { Estudos sociais; } \\
\text { História. }\end{array}$ \\
\hline $\begin{array}{l}\text { Personagens } \\
\text { - Dimensão espacial }{ }^{(2)} \\
\text { - Dimensão mental } \\
\text { - Personagens e } \\
\text { emoções }^{(3)}\end{array}$ & $\begin{array}{l}\text { - Alice; } \\
\text { - Ming (mãe); } \\
\text { - John (pai); } \\
\text { - Brad (amigo } \\
\text { imaginário). }\end{array}$ & $\begin{array}{l}\text { Artes; } \\
\text { Leitura e escrita de } \\
\text { textos digitais; } \\
\text { Alfabetização } \\
\text { midiática; } \\
\text { Comunicação; } \\
\text { Inteligência } \\
\text { emocional; } \\
\text { Multiculturalidade; } \\
\text { Globalização; } \\
\text { Gastronomia. }\end{array}$ \\
\hline $\begin{array}{l}\text { Efeitos } \\
\text { - Transições }{ }^{(1)} \\
\text { - Sonorização - } \\
\text { diálogos, trilha }^{(4)} \\
\text { sonora e ruídos }^{(4)} \\
\text { - Dimensão mental }\end{array}$ & $\begin{array}{l}\text { - Movimentos } \\
\text { visuais e sonoros; } \\
\text { - Composição dos } \\
\text { cenários. }\end{array}$ & $\begin{array}{l}\text { Produção } \\
\text { audiovisual; } \\
\text { Artes; } \\
\text { Desenho; } \\
\text { Música; } \\
\text { Informática; } \\
\text { Fotografia. }\end{array}$ \\
\hline $\begin{array}{l}\text { Narrativas } \\
\text { - Tempo e pessoa } \\
\text { - Narrativa mimética } \\
\text { interna }^{(2)} \\
\text { - Dimensão formal e } \\
\text { pragmática }^{(2)} \\
\text { - Interface narrativa } \\
{ }^{(3)}\end{array}$ & $\begin{array}{l}\text { - Acontecimentos } \\
\text { na perspectiva da } \\
\text { Alice; } \\
\text { - Descrição do Jeep; } \\
\text { - Percepção da } \\
\text { Alice; } \\
\text { - Sequência de } \\
\text { eventos. }\end{array}$ & $\begin{array}{l}\text { Português; } \\
\text { Redação criativa; } \\
\text { Produção de textos } \\
\text { digitais (fotografia, } \\
\text { vídeo, animação e } \\
\text { desenho). }\end{array}$ \\
\hline
\end{tabular}

Quadro 1- Resumo. (1) Gosciola [2003], (2)Ryan [2006], ${ }^{(3)}$ Bizzocchi [2007], ${ }^{(4)}$ Filatro e Cairo [2015], ${ }^{(5)}$ Ryan [2004]. Fonte: Elaboração das autoras. $16^{\circ}$ Ergodesign - Congresso Internacional de Ergonomia e Usabilidade de Interfaces Humano Tecnológica: Produto, Informações Ambientes Construídos e Transporte

$16^{\circ}$ USIHC - Congresso Internacional de Ergonomia e Usabilidade de Interfaces Humano Computador

CINAHPA | 2017 - Congresso Internacional de Ambientes Hipermídia para Aprendizagem.

\section{Considerações}

Os temas a serem explorados, mostrados no Quadro 1 - coluna 3, ratificam a pluralidade de leituras citada por Filatro e Cairo [2015]. Entretanto, entende-se que os professores e equipes educacionais devem desenvolver competências midiáticas ${ }^{2}$ para poderem perceber as possibilidades de conexão entre as pistas deixadas pelo mundo ficcional e os conteúdos dos temas a serem explorados.

$\mathrm{Na}$ análise por meio do close reading constatou-se que o mundo ficcional foi preparado de forma cuidadosa. Atribui-se em parte à equipe formada por uma novelista e um artista digital. Essa composição corrobora a sugestão de Jenkins [2004] de incluir técnicas de ambientação e contação de histórias para o design. No caso, ele referiu-se ao design de games; porém, neste trabalho propõe-se o mesmo para o design instrucional de recursos educacionais. A desconstrução do mundo distribuída em cenas, personagens, efeitos e narrativas mostrou que na costura das dimensões temporal, espacial, mental formal e pragmática há uma linha de coerência cujo fio condutor é a busca. Nesse fio, observa-se a incompletude das passagens, o que ratifica Pence [2012] na afirmação de que uma obra transmídia deve ser incompleta. As lacunas das passagens são os pontos para explorar, interpretar e expandir que devem ser aproveitadas pelos professores como oportunidades para as ligações com os conteúdos.

Verificou-se também que a novela digital apresenta as formas que são pré-condições para experiências narrativas imersivas citadas por Jenkins [2004], a saber: espaços evocativos, isto é, há passagens capazes de reproduzir na imaginação ou de trazer lembranças de associações narrativas preexistentes; espaços de representação, ou seja, apresenta pistas para ações a serem realizadas; incorporação de

${ }^{2}$ Competência midiática, segundo Pérez-Rodríguez e Delgado [2012], mescla competência audiovisual e competência digital. A primeira envolve conhecimentos, habilidades e atitudes relacionadas aos meios de comunicação de massa e à linguagem audiovisual; enquanto a segunda, a capacidade de busca, processamento, comunicação, criação e difusão por meio das tecnologias. 


\section{$16^{\circ}$ \\ ERGODESIGN USIHC CINAHPA}

$16^{\circ}$ Ergodesign - Congresso Internacional de Ergonomia e Usabilidade de Interfaces Humano Tecnológica: Produto, Informações Ambientes Construídos e Transporte

$16^{\circ}$ USIHC - Congresso Internacional de Ergonomia e Usabilidade de Interfaces Humano Computador

CINAHPA | 2017 - Congresso Internacional de Ambientes Hipermídia para Aprendizagem. narrativas, pois trata-se de uma investigação, com percursos, pistas e enigmas para a construção de caminhos; e, narrativas emergentes que se traduzem na capacidade de elaboração da própria história a partir das variáveis do mundo ficcional. Ao identificar essas formas, a sugestão para professores é de aproveitá-las para planejar as situações de aprendizagem incluindo-as em estratégias pedagógicas e atividades. A título de exemplo, uma alternativa é valer-se da Taxonomia de Bloom Revisitada $^{3}$ [AIRASIAN; MIRANDA, 2002], as situações de aprendizagem que se utilizam de espaços evocativos podem explorar conteúdos relacionados à dimensão do conhecimento factual ou conceitual em processos cognitivos como lembrar e entender (Geografia, História, por exemplo). De forma similar, as narrativas emergentes podem explorar os conteúdos que dão margem à dimensão do conhecimento metacognitivo em processos cognitivos mais elevados como avaliar e criar, adequados a temas como multiculturalidade, redação criativa, arte, entre outros conteúdos.

Dentre os aspectos identificados nas observações, constatou-se que Inanimate Alice possui todas as características que tornam narrativas transmídia populares. Segundo Ryan [2013], são elas: $o$ prazer da experimentação, pois permite que os interatores criem suas próprias versões de produções, utilizando os dispositivos que preferirem ou tiverem disponíveis; a possibilidade de construção coletiva da história, provocada pelos conflitos e dúvidas que podem ser compartilhados em grupos ou comunidades; tempo customizável que vai além da mídia em si, ou seja, o interator ou os interatores podem decidir quais

\footnotetext{
${ }^{3}$ A Taxonomia de Bloom é utilizada como instrumento para apoiar o planejamento didático pedagógico. Em 1956, Benjamin Bloom (pedagogo, psicólogo e professor) organizou em uma taxonomia os tipos de aprendizagem e os objetivos a que correspondiam. Ela foi revista nos anos 1980 e remodelada na forma bidimensional. A dimensão Conhecimento divide-se em factual, conceitual, procedimental e metacognitivo. A outra dimensão, Processos cognitivos, é expressa pelos verbos lembrar, entender, aplicar, analisar, avaliar e criar. Fonte: Elaboração das autoras.
}

documentos buscar, consultar ou elaborar para explorar melhor o mundo da história; mídia descarregável, isto é, a disponibilidade de acessar o episódio quantas vezes necessitar, controlar quando parar ou repetir (no caso, o Inanimate Alice está disponível no website); retorno do investimento cognitivo, significa que pela energia que o interator investiu para construir o seu mundo particular, ele pode verificar o ganho cognitivo do seu esforço e pode voltar quando e quantas vezes quiser para elaborar novas versões. Vale salientar que oportunidades para experimentar e construir de forma coletiva são importantes ações a serem incluídas no planejamento. Independente dos conteúdos a serem desenvolvidos, essas ações envolvem as dimensões de conhecimento metacognitivo e processo cognitivo para criar, uma vez inseridos em uma atividade auxiliam na socialização e na colaboração, o que favorece o desenvolvimento de atitudes. Entende-se que aproveitar todas as características no planejamento das situações de aprendizagem pode despertar a motivação intrínseca dos estudantes. O retorno do investimento cognitivo dos estudantes poderá ser expresso pelas construções realizadas, sendo estas os indicadores de sucesso do aprendizado. $\mathrm{O}$ Quadro 2 apresenta a síntese do que foi identificado como elementos potenciais:

\begin{tabular}{|l|l|}
\hline Elementos & Itens e oportunidades \\
\hline $\begin{array}{l}\text { Das experiências } \\
\text { narrativas imersivas }\end{array}$ & $\begin{array}{l}\text { - espaços evocativos como oportunidade para } \\
\text { aprendizagem significativa }{ }^{4} ; \\
\text { - espaços de representação e incorporação de } \\
\text { narrativas são oportunidades para atuação e } \\
\text { construção de conhecimento; } \\
\text { - narrativas emergentes como oportunidade de } \\
\text { criação e colaboração. }\end{array}$ \\
\hline $\begin{array}{l}\text { Das narrativas } \\
\text { transmídia } \\
\text { populares }\end{array}$ & $\begin{array}{l}\text { - prazer da experimentação e construção para desenvolvimento metacognitivo; } \\
\text { - tempo customizável e mídia descarregável } \\
\text { em estratégias de busca e desenvolvimento da } \\
\text { autonomia; } \\
\text { - retorno do investimento cognitivo para } \\
\text { atividades de avaliação do percurso de } \\
\text { aprendizagem }\end{array}$ \\
\hline
\end{tabular}

Quadro 2 - Síntese dos elementos e oportunidades de uso. Fonte: Elaboração das autoras.

\footnotetext{
${ }^{4}$ A teoria da aprendizagem significativa foi postulada por Ausubel, em 1963. Segundo ele, a atribuição de significado depende do que o estudante já sabe. Os novos conhecimentos são ancorados em estruturas anteriores (FILATRO; CAIRO, 2015).
}

Realização:
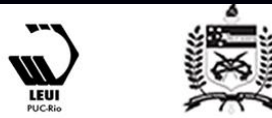


\section{$16^{\circ}$ \\ ERGODESIGN USIHC CINAHPA}

$16^{\circ}$ Ergodesign - Congresso Internacional de Ergonomia e Usabilidade de Interfaces Humano Tecnológica: Produto, Informações Ambientes Construídos e Transporte

$16^{\circ}$ USIHC - Congresso Internacional de Ergonomia e Usabilidade de Interfaces Humano Computador

CINAHPA | 2017 - Congresso Internacional de Ambientes Hipermídia para Aprendizagem.
Por fim, sugere-se utilizar a taxonomia de Bloom revisitada para planejamento das situações de aprendizagem por possibilitar uma visão sistêmica.

\section{6 À guisa de conclusão}

Este artigo apresentou os resultados da análise do mundo ficcional de um artefato transmídia de referência na Educação. Para tanto, aplicou-se o método Close Reading, utilizando a lente da poética transmídia com o objetivo de identificar os elementos potenciais para auxiliar professores no planejamento de situações de aprendizagem que levem os estudantes a uma participação mais ativa. $\mathrm{O}$ método mostrou-se adequado para investigações dessa natureza.

O estudo permitiu identificar os elementos das experiências narrativas imersivas e das características das narrativas transmídia populares do mundo ficcional da novela digital como possíveis responsáveis pela referência na Educação. Sugere-se aos professores que tais elementos sejam incluídos nos planejamentos em estratégias pedagógicas e atividades para promover a participação ativa dos estudantes. Desta forma, acredita-se ser possível usufruir de uma cultura de rede na qual os estudantes estão inseridos, aberta a múltiplas formas de leitura e produção de conhecimento.

O desafio está na formação dos professores que ainda não desenvolveram competências midiáticas para perceber e poder utilizar desses elementos aliados aos conteúdos em seus planos didáticos. Para esses, sugere-se investir na educação continuada por meio de cursos, oficinas, participação em comunidades, literatura especializada, assim como a imersão no mundo digital para aprender junto aos estudantes.

Para os professores abertos aos novos desafios, recomenda-se que o planejamento de situações de aprendizagem utilizando os elementos seja realizado com o apoio da Taxonomia de Bloom Revisitada por uma equipe de docentes de diferentes disciplinas e de forma colaborativa. Desta maneira, os mesmos estarão desenvolvendo a alfabetização midiática no processo e ampliando as possibilidades de aprendizagem. Acredita-se que os elementos também auxiliem designers instrucionais e desenvolvedores de recursos educacionais a avaliarem o potencial transmídia durante o processo de elaboração dos mesmos.

Para estudo futuro, sugere-se (a) a análise de outros artefatos transmídia a fim de verificar se há novos elementos a acrescentar; (b) o desenvolvimento de um modelo de planejamento utilizando a taxonomia de Bloom Revisitada e os elementos da transmídia que contemplem cuidados para a acessibilidade de estudantes com deficiência visual e deficiência auditiva e (c) a aplicação e validação do modelo por professores em turmas de estudantes de diferentes níveis educacionais.

Espera-se, com este estudo, contribuir para que professores, designers instrucionais e desenvolvedores possam aproveitar o potencial da computação móvel, das redes sociais e da convergência das mídias, ampliando experiências brasileiras e os conhecimentos acerca da transmídia na Educação.

\section{Referências}

AIRASIAN, P. W.; MIRANDA, H. The Role of Assessment in the Revised Taxonomy. In: Theory into Practice. Ohio: College of Education. The Ohio State University, v. 41. n.4, 2002. p. 249-254.

BIZZOCCHI, J. Games and Narrative: an Analytical Framework. In: Loading, Online Journal of the Canadian Game Studies Association. [S.1.]: [s.n.], v. 1, 2007.

BORDWEL, D. The Poetics of Cinema. Nova Iorque: Routledge, 2008.

BRASIL. PRESIDÊNCIA DA REPÚBLICA. CASA CIVIL. Lei no 12.965 , de 23 de abril de 2014. Princípios, direitos e deveres para o uso da Internet no Brasil, 2014. Disponivel em: <http://www.planalto.gov.br/ccivil_03/_ato20112014/2014/lei/112965.htm>. Acesso: 20 dez. 2016.

COMITÊ GESTOR DA INTERNET NO BRASIL. Pesquisa sobre o uso das tecnologias de informação e comunicação nas escolas brasileiras: 


\section{$16^{\circ}$ \\ ERGODESIGN USIHC CINAHPA}

TIC educação 2015. São Paulo: Comitê Gestor da Internet no Brasil, 2016.

FILATRO, A.; CAIRO, S. Produção de conteúdos educacionais. São Paulo: Saraiva, 2015.

GOSCIOLA, V. Roteiro para as novas mídias: do cinema às mídias interativas. São Paulo: Senac São Paulo, 2003.

INANIMATE Alice - Episódio 1 - China. Produção: Ian Harper. [S.1.]: BradField Company Ltd. 2005.

JENKINS, H. Game Design as Narrative Architecture. In: WARDRIP-FRUIN, N.; HARRIGAN, P. First Person: New Media as Story, Performance, and Game. Cambridge MA: MIT Press, 2004. p. 118 - 130.

JENKINS, H. Cultura da convergência. Trad. Susana Alexandria. São Paulo: Aleph, 2009.

KÜLLER, J. A.; RODRIGO, N. F. Metodologia de desenvolvimento de competências. Rio de Janeiro: Senac Nacional, 2013.

MICHAELIS. Moderno Dicionário da Língua Portuguesa, 2016. Disponivel em:

$<$ http://michaelis.uol.com.br/moderno/portugues/inde x.php>. Acesso em: 26 Maio 2016.

PENCE, H. E. Teaching with Transmedia. Journal of Educational Technology Systems, Annual, 40(2), 2012. 131.

PÉREZ-RODRÍGUEZ, M. A.; DELGADO, Á. De la competencia digital y audiovisual a la competencia mediática: dimensiones e indicadores [From Digital and Audiovisual Competence to Media Competence: Dimensions and indicators]. Comunicar, Madrid, n. 39, p. 25-34, 2012. Disponível em http://dx.doi.org/10.3916/C39-2012-02-02. Acesso: 26 janeiro 2016

PRIMO, L. et al. Transmídia na Educação - Link para Inclusão. XIX Congresso da Sociedade Iberoamericana de Gráfica Digital 2015. $16^{\circ}$ Ergodesign - Congresso Internacional de Ergonomia e Usabilidade de Interfaces Humano Tecnológica: Produto, Informações Ambientes Construídos e Transporte

$16^{\circ}$ USIHC - Congresso Internacional de Ergonomia e Usabilidade de Interfaces Humano Computador

CINAHPA | 2017 - Congresso Internacional de Ambientes Hipermídia para Aprendizagem.

Florianópolis: Editora Edgard Blücher. 2015. p. 609617.

PROSE, F. Para ler como um escritor. Rio de Janeiro: Zahar, 2013.

RODRIGUES, P.; BIDARRA, J. Transmedia storytelling and the creation of a converging space of educational practices., 9(6), pp. 42-48. International Journal of Emerging Technologies in Learning, 2014. 42-48.

RYAN, M.-L. Will New Media produce New Narratives. In: RYAN, M.-L. Narratives across Media: the Languages of Storytelling. Lincoln Nebraska: University of Nebraska Press, 2004. p. 337-359.

RYAN, M.-L. Avatars of Story. Minneapolis MN: University of Minnesota Press, 2006.

RYAN, M.-L. Transmedial Storytelling and Transfictionality. Poetics Today, 34, n. 3, 2013. 361388.

SANTAELLA, L. Matrizes da linguagem e pensamento: sonora visual verbal - aplicações na hipermídia. São Paulo: Iluminuras, 2013.

TANENBAUM, J. G. Identity Transformation and Agency in Digital Narratives and Story Based Games. Tese. Burnaby: Simon Fraser University, 2015.

WAKI, F. Os heróis gregos e anglo-saxões ou as transformações de um paradigma. Dissertação. Campinas: Universidade Estadual de Campinas, 2015.

\section{Agradecimentos}

À CAPES, pela concessão de bolsa para a doutoranda Lane Primo.
Realização:

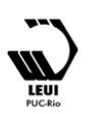

